\title{
Embodied appearance properties and subjectivity
}

Adaptive Behavior

$1-12$

(C) The Author(s) 2018

Reprints and permissions:

sagepub.co.uk/journalsPermissions.nav

DOI: $10.1|77 / 10597| 2318768460$

journals.sagepub.com/home/adb

@SAGE

\section{Miguel Ángel Sebastián}

\begin{abstract}
The traditional approach in cognitive sciences holds that cognition is a matter of manipulating abstract symbols following certain rules. According to this view, the body is merely an input/output device, which allows the computational system - the brain - to acquire new input data by means of the senses and to act in the environment following its commands. In opposition to this classical view, defenders of embodied cognition (EC) stress the relevance of the body in which the cognitive agent is embedded in their explanation of cognitive processes. From a representationalist framework regarding our conscious experience, in this article, I will offer a novel argument in favor of EC and show that cognition constitutively - and no merely causally-depends upon body activity beyond that in the brain. In particular, I will argue that in order to solve the problem derived from the empirical evidence in favor of the possibility of shifted spectrum, representationalist should endorse the view that experiences concern its subject: the content of experience is de se. I show that this claim perfectly matches the phenomenological observation and helps explaining the subjective character of the experience. Furthermore, I argue that entertaining this kind of representation constitutively depends on bodily activity. Consequently, insofar as cognition depends on consciousness, it is embodied.
\end{abstract}

\section{Keywords}

Embodied cognition, consciousness, appearance properties, representationalism, de se representation, subjective character

Handling Editor: Ximena González-Grandon, National Autonomous University of Mexico, Mexico

\section{Introduction}

The traditional approach in cognitive sciences holds that cognition is a matter of computation, that is, of manipulating abstract symbols following certain rules. According to this view, the body is merely an input/output device, which allows the computational systemthe brain - to acquire new input data by means of the senses and to act in the environment following its commands.

In opposition to this classical view, defenders of embodied cognition (EC) stress the relevance of the body and the environment in which the cognitive agent is embedded in their explanation of cognitive processes. There is, however, a good deal of diversity in how such a relevance is spelled out - see Wilson (2002) for a review. Very often, EC is confused with situated cognition, the view that some cognitive processes cannot be isolated from the environmental conditions in which they take place. Despite the fact that sometimes the questions EC deals with are revealingly discussed together with situated cognition views (Clark, 2008; Rupert, 2009; Shapiro, 2011), in this article, I do not wish to discuss the relevance of the environment in cognition, but rather to focus on the pertinence of other parts of the organism, beyond the brain, in cognitive processes. In particular, I will argue in favor of a view in which consciousness constitutively depends on bodily activity beyond that of the brain - which uncontroversially is involved in consciousness and cognition. According to this view, insofar as cognition depends on consciousness, cognition is embodied.

Instituto de Investigaciones Filosoficas, Universidad Nacional Autónoma de México, Mexico City, Mexico

\section{Corresponding author:}

Miguel Ángel Sebastián, Instituto de Investigaciones Filosoficas, Universidad Nacional Autónoma de México, Circuito Mario de la Cueva s/n, Ciudad Universitaria Delegación Coyoacán, 04510 Mexico City, Mexico.

Email: msebastian@gmail.com 
Many of our mental states are phenomenally conscious, that is, they have phenomenal character, or to borrow Nagel's expression there is something it is like to be in them. Examples of conscious states are those one undergoes while looking at the ocean or at a red apple, drinking a glass of scotch or a tomato juice, smelling coffee or the perfume of a lover, and listening to the radio or a symphonic concert. Further examples are bodily sensations such as pains, hunger pangs, or orgasms. Emotions also have a characteristic feeling; just consider the radiant feeling at being happy or the languidness of depression. There is also a conscious states associated with mental imagery; for instance, when one imagines a paradisiacal beach or remembers one's first kiss.

The term cognition is used as an umbrella for different mental processes including perception, learning, remembering, judging, or problem-solving. Many of these cognitive processes seem to depend on phenomenally conscious states, the clearest case being perception. Although it is widely accepted that there is unconscious perception, ${ }^{1}$ this process typically involves the presence of conscious states. Likewise, remembering involves mental imagery and emotions. Problem-solving often depends on consciousness, not only because it commonly involves perception or mental imagery-for instance, to figure out counterfactual situations - but also because emotions seem to be involved in the process (Damasio, 1995; Duncan \& Barrett, 2007). It is therefore very plausible that if consciousness is embodied, so is cognition, at least to the same extent.

Phenomenally conscious states are intentional states: they represent the world as being a certain way. Still, it is not always the case that the world is that way, as in cases of illusions or hallucinations. ${ }^{2}$ The former observations make the claim that the intentional content of experience determines the phenomenal character of experience very plausible. In other words, if we call phenomenal properties the properties of my mental states that ground what it is like to undergo those states, phenomenal properties are some kind of representational properties. This is the thesis of representationalism. ${ }^{3}$

Although there is a tendency among defenders of embodied and situated cognition to deflate the role representations play in the explanation of cognition and stress other notions like that of autopoiesis (Di Paolo \& Thompson, 2014; Varela, Thompson, \& Rosch, 1991), or sensorimotor dependencies (Noë, 2005; O'Regan, 2011), is unclear - to say the least - that they get rid of them (Hutto \& Myin, 2013). That said, representationalism is an appealing theory for the project of naturalizing consciousness, assuming that the relation of representation can be naturalized. Any plausible naturalistic theory of mental content will commit representationalists to some weak form of situated cognition and embodiment - see, for instance, Cummins (1975); Dretske (1988); Millikan (1984); Mossio, Saborido, and
Moreno (2009); Neander (1991); and Papineau (1993). The relevant question in the debate is whether the role that the body or the environment play is constitutive rather than merely causal. ${ }^{4}$ My aim in this article is to offer a novel argument in favor of this strong form of EC. I will argue that the best theory of representationalism should embrace the thesis that phenomenal properties are embodied, independently of the general problem of explaining the relation of representation. This will show that even if we assume a representationalist starting point, we should end up with the conclusion that embodiment is constitutive of cognition.

In the following section, I will show that one of the most serious problems for representationalists is how to make sense of their claims, given the empirical evidence suggesting that there can be two normal individuals whose visual experiences are slightly different (their visual spectra is shifted with regard to each other) where none of them can be said to misrepresent. The experiences of such shifted individuals can be about the same property (have the same content) and that, nonetheless, the subjects undergo experiences with different character. This problem can be addressed if the content of experience concerns not only the environment but also the subject that is having the experience as such: the content of experience is de se, in having an experience one self-ascribes a certain property. In section "The phenomenology of subjectivity," I will argue that the view that the content of experience is constituted by self-ascribed properties perfectly matches the phenomenological observation. In the last section, I will explain in what sense these kinds of representational properties depend on embodiment.

\section{Representationalism and shifted spectrum}

Color perception in humans depends partially on particular light sensitive cells in the retina called cones. There are three kind of cones, each one responding mainly to light with a wavelength within a certain range, called accordingly long, medium, and short cones. They have peak wavelengths of close to 564-580, 534 545, and 420-440 nm, respectively. Lutze, Cox, Smith, and Pokorny (1990) have shown that standard deviation in peak sensitivity of the cones of normal subjects is $1-2 \mathrm{~nm}$. This variation is very important, if we consider the difference in peak sensitivity between long and medium cones. There are also a number of specific genetic divisions in the peak sensitivities on humans depending on sex, race and age (differences over $5 \mathrm{~nm}$ !! Neitz and Neitz (1998)). These differences are not always compensated by the visual system. Kraft and Werner (1994) study on the effect of aging on the visual system concludes that the visual system corrects certain alterations of the early stages of the visual system, in 
this case, in the retina, but also that these corrections are insufficient, especially at short wavelengths. These differences have been confirmed to influence the appearance of colors. Neitz, Neitz, and Jacobs (1993) showed that people whose cone's middle- or longwavelength sensitivity differ disagree about the proportion of the mixture of two colors required to obtain a third color.

While looking at a red apple, I have a phenomenally conscious experience as of red. According to representationalism, the phenomenal character of my experience is determined by the property of representing red. The empirical evidence presented above suggests that the phenomenal character of the visual experiences that two different subjects have while looking at the same red apple could be different - even if we assume that they are looking at the very same apple from the very same point of view under the same lighting conditions. If none of them can be said to misrepresent, then representationalism seems to be false, because both subjects have experiences with the same content but nevertheless differ phenomenologically: one is having, what we can

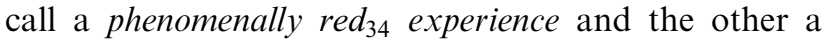
phenomenally red ${ }_{36}$ experience.

Representationalism can be saved by supposing that, whereas shifted subjects represent the object as being the same color-there is a content they both share, namely, the color of the apple, there is also a representational difference with respect to another property that is attributed to the object by the experience (Shoemaker, 1994). We might call these properties "appearance properties." The phenomenal character of experience is fully determined by these appearance properties.

A satisfactory characterization of such properties is complicated. Intuitively, they should satisfy the following constraints (Egan, 2006):

Difference. Shifted individuals should represent the apple as having different appearance properties.

Correctness. Shifted individuals should both represent the apple correctly.

Novelty. Appearance properties are not colors.

Possible-Sameness. It might be possible that one individual correctly attributes the same appearance to the apple that another individual correctly attributes to another object of slightly different color.

Contrariness. Correctly representing something as having the appearance property A should be incompatible with correctly representing it as having the appearance property B.

Shoemaker (2000) proposes as a candidate for appearance properties of the form being disposed to

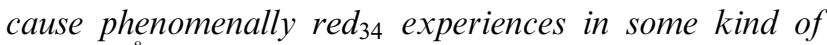
observer. There is an ambiguity in this characterization, as Egan argues, and none of the disambiguations seem to be a satisfactory option. The property which my experience attributes to the apple could be that of being disposed to cause phenomenally red $_{34}$ experiences in some kind of possible observer or in some kind of actual observer. The first option is not plausible, for nearly everything is disposed to cause phenomenally red $_{34}$ experiences in some kind of possible observer, and the same is true of phenomenally red $_{36}$ experiences. So, on the very plausible assumption that necessary coextensive properties are the same, shifted individuals would be attributing the same property to the apple, and therefore, Difference would not be satisfied. Shifted individuals would not represent the apple as having different appearance properties, but they would differ phenomenologically.

If we consider the second option, we can see that there are also two possible readings depending on the force of the term "actual" (Egan, 2006, pp. 505-506). The relevant property could be that of being disposed to cause phenomenally red ${ }_{34}$ experiences in some kind of observer who exists in the actual world, or it could be the property of being disposed to cause phenomenally red experiences in some kind of observer who exists in the world in which the object exists. The first option cannot be the characterization we are looking for. It restricts the kind of observers to the actual world, and therefore, it cannot account for merely counterfactual shifted spectra. The second reading faces similar counterintuitive consequences. According to this view, an apple of the very same color as the one I have in front of me would lack some appearance properties in a world where, for instance, there were no observers - it would therefore lack the disposition to cause phenomenally red $_{34}$ experiences in any observer in this world.

In order to solve these problems, we can focus on a certain kind of subjects, which would allow mere possible objects and kinds of subjects to be taken into consideration, something like having the disposition to cause phenomenally red ${ }_{34}$ experiences in subjects of type T. But this alternative is also problematic because PossibleSameness cannot be satisfied: if two shifted subjects belong to different types, then they cannot attribute the same appearance property to different objects, as is intuitively the case. Furthermore, Contrariness is not satisfied either.

Egan shows that the problem cannot be solved if we want to hold that we attribute some sort of property to the primary object of experience - the apple in our example. However, the problem is solved if we attribute what he calls "a centered feature," a subject-dependent property that can be expressed in English as something like being disposed to cause certain state in me. Technically, if properties are functions from possible worlds to extensions, centered features are function from a centered world (the dupla $<$ world, individual $>$ ) to extensions as we will see. It is then easy to see that attributing a centered feature to the primary object is 
equivalent to self-attributing a property (Egan, 2006; Lewis, 1979). The apple has this feature relative to a centered world in which I am the marked observer just in case the object is disposed to cause phenomenally red $_{34}$ experiences in me and also has the property relative to a centered world in which an individual whose spectrum is shifted with regard to mine, if the apple is disposed to cause phenomenally red $_{36}$ experiences in her. In this case, both subjects might correctly selfattribute the property of being in different perceptual relations - we will see this in further detail. This proposal fulfills all the desiderata, as Egan shows.'

One consequence of this proposal that some readers might find puzzling is the idea that centered features, and not properties, enter the content of experience. The experience concern the very same subject that is having the experience: the kind of representation that determines the phenomenology is a first-person or de se representation (Castañeda, 1966; Lewis, 1979). Egan presents this proposal as a price worth paying for saving representationalism. In the next section, I will argue that there is no drawback to this view and that a careful phenomenological observation reveals precisely that the content of experience is de se. In the last section, I will provide a more detailed characterization of this kind of representation and explain in what sense this representationalist view is committed to the embodiment thesis.

\section{The phenomenology of subjectivity}

Consider again the visual experience you have while looking at a red apple, the apple and its properties constitute what we can call "the primary object of perception." If representationalism is to deal with shifted spectrum, it better be, as we have just seen, that the experience concerns not only the primary object of perception but also about the subject of experience. Can we provide independent support for such a claim?

One might find such support in a priori reasoning. When Nagel introduced his famous locution, he emphasizes the fact that in having an experience there is something it is like for the subject to be in such state. However, it is not at all clear that the expression "there is something it is like for $\mathrm{X}$ to $\varphi$ " has any import to describe subjectivity as Byrne (2004) has shown (see Nida-Ruemelin (2017) for an argument immune to Byrne's objection). Similar ideas have been presented in different terms by different philosophers. Kant, for instance, argued that in order to account for what I have called the phenomenological observation, that is, for mental representations to be mine, we need to account for a certain sense of self and a certain sense of self-consciousness:

For the manifold representations, which are given in an intuition, would not be one and all my representations, if they did not all belong to one self-consciousness. As my representations (even if I am not conscious of them as such) they must conform to the condition under which alone they can stand together in one universal self-consciousness, because otherwise they would not all without exception belong to me. (B132, B133, my emphasis)

More recently, Flanagan (1993) has argued that phenomenal consciousness involves some weak sense of self-consciousness, not only in the sense that there is something it is like for me to have the experience but also in my experiencing a quality as mine. Burge (2007) makes a related point:

$[P]$ henomenal consciousness in itself involves phenomenal qualities being conscious for, present for, the individual. They are presented to the individual consciousness. This presentational relation is fundamental to phenomenal consciousness. I think that this relation can be recognized $a$ priori, by reflection on what it is to be phenomenally conscious. Phenomenal consciousness is consciousness for an individual. Conscious phenomenal qualities are present for, and present to, an individual. (p. 405, my emphasis)

Bermudez (1998) has also discussed non-conceptual forms of self-consciousness that are "logically and ontogenetically more primitive than the higher forms of selfconsciousness that are usually the focus of philosophical debate" (p. 274). From the neurological perspective, the idea that a sense of self is required for experience has been defended by Damasio $(2000,2010)$ and Pollen (2008).

Alternatively, one could also appeal to the transitivity principle, which Rosenthal suggests that is justified by our folk psychology. However, appealing to our folk psychology does not seem to be a satisfactory option unless we can justify in turn the beliefs that constitute it and, in particular, those that refer to our experiences (Kriegel, 2009). For this reason, phenomenological observation seems to be the most straightforward way to motivate the claim that something about the subject is conveyed by the experience. It has been claimed that experiences have a distinctive firstpersonal character, which, for example, Kriegel (2009) calls it "for-meness" and Block (2007a)"me-ishness." A similar insight can be found in the phenomenological tradition, which contrasts, at least, two forms of selfconsciousness: a reflective and a pre-reflective one. In reflective self-consciousness, one has access to oneself in the same sense that one has access to other objects. In this sense, the self can be very relevant and probably the most valuable, but it is just another object of experience, as it might be an apple or a golf course and can therefore be distinguished from the experiencing subject, it is a mere Gegenstand. In pre-reflective self-consciousness, however, one is aware of oneself as the 
subject of experience. Gallagher and Zahavi (2006) present this idea as follows:

There is something it is like to taste chocolate, and this is different from what it is like to remember what it is like to taste chocolate, or to smell vanilla, to run, to stand still, to feel envious, nervous, depressed or happy, or to entertain an abstract belief. Yet, at the same time, as I live through these differences, there is something experiential that is, in some sense, the same, namely, their distinct first-personal character. All the experiences are characterized by a quality of mineness or for-me-ness, the fact that it is I who am having these experiences. All the experiences are given (at least tacitly) as my experiences [. . .] All of this suggests that first-person experience presents me with an immediate and non-observational access to myself, and that consciousness consequently entails a (minimal) form of self-consciousness. To put it differently, unless a mental process is pre-reflectively self-conscious there will be nothing it is like to undergo the process, and it therefore cannot be a phenomenally conscious process.

It seems that the experience conveys that the subject herself is related to the primary object rather than just conveying that certain property is instantiated by the object; just by virtue of having the experience, the subject is in a position to immediately form a belief about the relation she bears to the primary object. All these observations support the claim that our experiences convey something not only about the primary object of experience but also about ourselves.

Now, understanding the sense in which the experience allegedly conveys something about the subject is crucial to the discussion. When a subject $\mathrm{S}$ has a visual experience, her experience does not conveys that $\mathrm{S}$ is in certain perceptual state - that $\mathrm{S}$ is confronted with certain object - $\mathrm{S}$ is not an object of experience, pace Brentano), rather it conveys that she herself (Castañeda, 1966) is confronted with certain kind of object: the kind of representation that characterizes the experience is de se (Lewis, 1979; Perry, 1979). So, a theory of consciousness has to explain the fact that no matter what the primary object of the experience is (say certain features of the apple in my experience as of red apple), the experience is also directed to myself, not as an object but rather as an experiencing subject. In accordance to the conclusion of the previous section, the content of my experience is not merely that suchand-such is the case, but that such-and-such is presented to myself. In phenomenally conscious experiences, I do not merely attribute certain properties to the object causing the experience and I self-attribute the property of being perceptually related to an object with certain properties.

The claim that something about oneself is conveyed by the experience tends to be resisted because of two reasons. First, some people tend to believe that de se representation is allegedly too demanding. This would lead to the undesired consequence that cognitively simple animal and human babies would be unable to undergo conscious experiences. The second reason is related to the ontological commitments of such a theory, in particular, whether we would need to postulate some kind of suspicious entity like the self. However, both objections are misguided in the absence of a theory that accounts for what is required from a system to entertain that kind of representation. In the sequel, I will dispel these worries by sketching a naturalistic theory of de se representation (Sebastián, 2012). According to this theory, this form of representation is neither too demanding nor committed to any mysterious entity. However, it is committed to a strong sense of embodiment: de se representation constitutively and not merely causally depends upon body activity beyond that of the brain.

\section{Consciousness, de se representation, and embodiment}

A very popular view regarding mental content, and one that I will assume here, maintains that the role of mental states is to distinguish between different possibilities (Stalnaker, 1999). Traditionally, it has been considered that mental states are correct or adequate depending on the way the world might be. That is, they divide the space of possibilities into sets of possible worlds. An example might be helpful at this point. Consider the belief that the president of USA is misogynist and racist. This belief distinguishes two ways the world might be. It might be the case that the president of USA is misogynist and racist or that he is not. It also takes part for one of these sets, thereby determining a function from possible worlds to truth value or correctness. So, we say that such belief is correct if the actual world is such that the president of USA is misogynist and racist and false or incorrect otherwise; we attribute a property to the president of USA and such attribution is adequate or correct if the president has such property and false otherwise. What is required next is a theory of mental content, that is, a theory that explains what is required from a system in order to make "partitions in the space of possibilities" or "attributions of properties."

In the literature, we find several theories of mental content. These theories typically appeal to the notion of indication understood as some sort of covariance between the vehicle of representation and its object. The underlying idea is that a mental state represents what causes it in "normal conditions"-in order to accommodate the idea of misrepresentation, as we do not want a mental state to represent whatever causes it. Now, "normal conditions" is a normative notion not acceptable in a naturalistic framework. The most 
popular route to unpack this idea is by means of the biological function (Millikan, 1984). As a result, a representational state is one that has the biological function to indicate that such-and-such is the case, where such-and-such is the content. The biological function is the one that determines, among all the things the state indicate, which one is represented: ${ }^{10}$ attributing property $\mathrm{P}$ is a matter of being in a state that has the biological function of indicating property $\mathrm{P}$.

The problem for this view derives precisely from mental states that concern the subject itself as such, that is, of the de se representations. Compare my belief that M.Á.S. is drinking coffee and the belief that the only philosopher with a green t-shirt writing an article on embodiment in La Roma is drinking coffee. It seems clear that I can have one without having the other, but it does not seem the case that they demand the same from the current world and, therefore, we can easily capture the differences in terms of possible worlds. Now consider, on the contrary, my belief that I (myself) am drinking coffee. As I suggested before, it seems that I can have the latter without having the first if for any reason I ignored the fact that I am M.Á.S. However, both seem to demand the same from the world, that is, that a certain individual is drinking coffee. For this reason, Lewis suggests that de se representations do not determine partitions in the space of possibility in possible worlds but in centered worlds; that is, sets of pairs of possible worlds and individuals $(<w, i>)$.

If we can think of possible worlds as ways the world might be, then we can think of the centered worlds as the way a world is for an individual (Egan, 2006). Thus, the belief expressed by the sentence "I wrote about the plurality of worlds" is a belief that Lewis and I can share. To evaluate its correctness, we do not only need a world but also an individual. It is correct with respect to the pair $<w_{@}$, Lewis $>$, but false with respect to the pair $<w_{@}, M S>$. In this sense, de se representations determine functions from centered worlds to truth values.

I have considered that mental states make partitions in space of possibilities and what they consist of. The next question that arises is: What it takes to make the kind of partitions that de se representations make? If in order to make partitions into possible worlds, what we need is a theory that explains how we attribute properties, what is needed in the case of representations of oneself, is a theory of self-attribution of properties (Lewis, 1979). When I believe that I wrote "On the plurality of worlds," I self-attribute the property of having written the work in question. The belief is false because I do not have such property. When Lewis has the very same belief, he also self-attributes the same property. But he indeed has it, and hence, his belief is correct. Continuing with the process of unraveling the nature of this type of representations, we need to understand what is required from a system in order to self-attribute a property. Although there are theories that attempt to explain what it takes to attribute a property, for the reasons we have seen, self-attribution of $\mathrm{S}$ is not reducible to the attribution of properties to S by S. Lewis (1979) does not have many clues and simply states that "Selfascription of properties is ascription of properties to oneself under the relation of identity" (p. 543). We need a new theory.

In the case of self-attributions, it is not enough to be in a state that has the function to indicate that suchand-such is the case, we rather need a state that has the function to indicate that such-and-such is the case for the very same individual that is doing the representation. But what kind of entities should we consider as centers of our semantics? What kind of entity is an individual? In order to answer this question, we should think of the kind of entities that are susceptible that have experiences. The most straightforward reply within a naturalist framework points toward organism. But, what is an organism? A widely accepted view in biology holds that living organisms are self-maintaining systems, systems that favor the conditions for their own maintenance. In philosophy, the notion of selfmaintaining system has a long history, which dates back to Aristotle (Godfrey-Smith, 1994; McLaughlin, 2001) and was popularized by cyberneticians in contemporary science. More recently, many scientists started to migrate from the cybernetic approach to the thermodynamic view, following the work of Ilya Prigogine on dissipative structures and their role in thermodynamics. These dissipative structures would be the minimal expression of self-maintenance. They are systems in which a huge number of microscopic elements adopt a global, macroscopic structure in the presence of a specific flow of energy and matter in far from thermodynamic equilibrium conditions (Mossio et al., 2009, p. 822), a macroscopic structure with a very low entropy.

This technical notions can be easily illustrated by means of an example. Consider a heap of sand. One can grab a handful of sand, let the sand fall, and there will still be a heap of sand: there are multiple ways the grains of sand might be rearranged such that there continue being a heap of sand. Compare it with a sandcastle; there are less ways the grains might be rearranged so that the castle remains. Entropy measures this fact: How many ways the constituents can be organized at the micro level - the grains of sand - consistent with having the same structure at the macro level-the heap or the castle; or put more formally, entropy is a logarithmic measure of the number of states with significant probability of being occupied. The heap of sand is therefore an organization with a higher entropy than the castle. Now, the second law of thermodynamics, which states that the entropy of a system should increase or otherwise remain constant, can be 
intuitively understood by considering the tendency of a sandcastle to end up as a heap.

Organisms are systems with low entropy (systems that work far from thermodynamic equilibrium); they admit certain internal variations, but such variations have to be kept within very restricted boundaries. They are entities that change continuously, remaining, nonetheless, as functional unities, as unique systems, during the life of the organism. Organisms have the capacity to keep a stable internal condition compensating external and internal changes through exchange of matter and energy with the exterior - this is known as "homeostatics." The idea that I will develop in what follows is that, if this is what organisms are, then it seems reasonable to ground a theory of self-attribution in those invariants and in the mechanisms responsible for such stability.

Damasio $(2000,2010)$ makes an interesting proposal in this direction presenting his notion of proto-self. The proto-self is an integrated collection of neural patterns distributed over the brain that represent the most stable aspects of the physical structure of the organism and are involved in the process of regulating the organism's state." According to Damasio, the proto-self is a structure that does not just regulate the homeostatic processes of the organism, monitoring the extra-cellular environment (the internal milieu) but also, for example, the musculoskeletal structure and the visceral musculature. Damasio argues that these neural patterns are constitutive of the neural mechanisms underlying our conscious experience, and I will make use of it in my elaboration of the conditions under which experiences come to have the required de se content. The idea is to explain how an organism comes to self-attribute a property by means of the interaction of the proto-self with what I will call "proto-qualitative states." So, conscious states are accordingly constituted by the following two structures - plus the neural structures needed for the required interaction:

1. The proto-self: a brain structure that has the function of monitoring the organism invariants and regulating the homeostasis of the organism. It regulates the internal environment and tends to maintain a stable, constant condition required by the selfmaintaining system; the stability required for life.

2. Proto-qualitative state: a brain structure that has the function of indicating that such-and-such a state of affairs obtains in the world-for example, the function of indicating that there is a red object.

We have different kinds of experiences, like the one we have when looking at an apple and the one we have when looking at the open sea. These different states are constituted by different proto-qualitative states. Protoqualitative states are not phenomenally conscious, they don't have the required (de se) content and neither is the proto-self. It is the interaction between both of them that gives rise to a phenomenally conscious mental state because such a complex will have the function of indicating that the very same organism that the proto-self regulates is being affected by the object the proto-qualitative state represents. Here is an example:

When I look at a my computer, I undergo a phenomenally conscious experience. My visual system will generate a representation of the properties of the computer; this is a proto-qualitative state (PQ). But, as I just mentioned, this is still an unconscious representation. Moreover, the organism has a subsystem, the proto-self, that monitors and controls the homeodynamics of the organism and other invariants. The proto-self monitors the status of certain internal states like the extra-cellular fluid environment, the musculoskeletal structure, and the visceral musculature. Now, this latter state is altered by the processing of the computer: there will be changes in the retina or in the muscles that control the position of the eyeball, but also changes in the smooth musculature of the viscera, at various places of the body, corresponding to emotional responses, some of them innate. This interaction will explain why the content of the complex state constituted by the proto-self and the proto-qualitative state concerns the subject in the required sense: it is a de se representation. According to the theories we are considering, the content of a state depends upon what the state has the biological function of indicating (of tracking information about). The function of the complex that the proto-self and the proto-qualitative state(s) comprise is neither to indicate an object with, say, such-and-such surface reflectance nor to indicate, for example, that such-and-such a bodily state obtains, but rather to indicate that the very same system that is doing the representing-given that the proto-self, which is responsible for keeping the organism as what it essentially is, is part of the complex - is in a certain perceptual state. When an organism $\mathrm{O}$ is in this complex state, it neither merely attributes a property to another object nor merely attributes a property to $\mathrm{O}$, it rather self-attributes a property - that of being in a certain perceptual state. $O$ attributes a property to itself, to the very same organism that the proto-self regulates, "under the relation of identity" (Lewis, 1979, p. 543): the system attributes the property to the very same system that is doing the representing without any need of an identification. This complex state represents that the organism itself* (Castañeda, 1966) is presented with an object that PQ represents.

We can then look for the neural structures that would implement this complex. The proto-self would correspond to several brain stem nuclei including the tegmentum, the hypothalamus, the insular cortex, and S2 (Damasio, 2000, 2010); the proto-qualitative states would be implemented in different areas of the neocortex depending on the modality, like the visual cortex in the case of a visual experience. Finally, we should be 
after the structures that make the interaction between the proto-self and the proto-qualitative state possible. These areas should have ramifications leading to the areas corresponding to the proto-self as well as the proto-qualitative state and there being some evidence that suggest that they play a role in giving rise to conscious experiences. Example of these areas are superior colliculi, the anterior cingulate, ${ }^{12}$ the thalamus, and the medial parietal cortex (See Damasio $(2000,2010)$ and Laureys and Tononi (2008) for empirical evidence suggesting that these areas are constitutive of the neural correlate of our conscious experience).

\section{I. Self-Involving Representationalism and the shifted spectrum}

In this section, I will try to get clear about the way the presented view handles cases of shifted spectrum. This will further help to clarify the theory.

Consider a red apple, which, in normal lighting conditions, reflects light with a wavelength of, say, $650 \mathrm{~nm}$ - the apple does not reflect light with a unique wavelength, but we can abstract from this problem.

Marta's visual system and mine are slightly different and we undergo slightly different experiences when we look at the very same apple under the very same lighting conditions. Both experiences are correct. When Marta and I undergo these experiences, we are in different proto-qualitative states, $P Q_{2}$ and $P Q_{1}$, respectively. $P Q_{1}$, a state of my organism, has the function of indicating what is disposed to cause it in normal conditions. In these cases, we can assume that such normal conditions would be something like "via the particular visual path $_{P Q 1}$ under particular lighting conditions $P Q 1 . "{ }^{13}$ An object has the property that $P Q_{1}$ represents only if the object is disposed to cause the activation of $P Q_{1}$ in an organism like mine via the particular visual path $P Q 1$ under particular lighting conditions ${ }_{P Q 1}$. If an object reflects light with a wavelength of $650 \mathrm{~nm}$ in these lighting conditions, then it can cause $P Q_{1}$ via the particular visual path $_{P Q 1}$. The surface of the apple reflects light, in these lighting conditions, with a wavelength of $650 \mathrm{~nm}$ and is therefore represented by $P Q_{1}$.

In the case of Marta, an object has the property that $P Q_{2}$ represents only if the object is disposed to cause the activation of $P Q_{2}$ in an organism like Marta's via the particular visual path ${ }_{P Q 2}$ under particular lighting conditions $_{P Q 2}{ }^{14}$ If an object reflects light with a wavelength of $650 \mathrm{~nm}$, in these lighting conditions, then it can cause $P Q_{2}$ via the particular visual path ${ }_{P Q 2}$. The surface of the apple does so and is therefore represented by $P Q_{2}$.

$P Q_{1}$ interacts with my proto-self, the system that monitors and controls the homeodynamics of my organism. The state that results from this interaction is a phenomenally conscious mental state. This state represents that the organism is presented with an object that is disposed to cause $P Q_{1}$ in normal conditions (via particular visual path ${ }_{P Q 1}$ under particular lighting conditions $\left._{P Q 1}\right)$. When the organism is in this state, it attributes to itself the property of being presented with an object that is disposed to cause $P Q_{1}$ in normal conditions: it attributes to the object a centered feature.

Marta, however, attributes to herself the property of being presented with an object that is disposed to cause $P Q_{2}$ in normal conditions. Marta correctly attributes to the apple a different appearance property. Marta's experience and mine differ in character because we are self-attributing different properties, that is to say, we are attributing to the apple different centered features. Both experiences are, nevertheless, correct.

Imagine that Marta can be in a proto-qualitative state $P Q_{1}$ whose function is to indicate what produces it via the particular visual path ${ }_{P Q 1}$ under particular lighting condition $S_{P Q 1}$. In the case of Marta, an object is disposed to cause $P Q_{1}$ via particular visual path $P Q 1$ if the object can reflect light under particular lighting conditions $_{P Q 1}$ with a wavelength of $654 \mathrm{~nm}$. The fire engine on the corner of her street can reflect light with a wavelength of $654 \mathrm{~nm}$ under particular lighting conditions $_{P Q 1}$ and therefore is represented by $P Q_{1}$ in Marta's organism. Imagine further that this state interacts with her proto-self. The corresponding phenomenally conscious state represents than the organism is presented with an object that is disposed to cause $P Q_{1}$ in normal conditions. When she looks at the fire engine, she undergoes a phenomenally conscious experience with the very same character as the one I undergo when I look at the red apple. I attribute the same centered feature to the apple that Marta attributes to the fire engine; we are both attributing to ourselves the same property. Both attributions are, again, correct.

\subsection{Objections and rejoinders}

One possible objection to the proposal I have made is that the role of the proto-self structures in consciousness can be seen as causal and not constitutive. ${ }^{15}$ This would weak the claim that phenomenology is embodied, because it would not be constitutively so. One way of presenting this objection is by asking whether someone whose blood chemicals were regulated by an external computer that did not interact with her mental representations would be phenomenally conscious.

It is important to note that the notion of function required for representation must be such that a trait has a function even if it fails to perform such a function (a case of misrepresentation) and even if it never does so. Consider the kidney of a patient suffering from a renal failure condition. We say that her kidney is malfunctioning, it is not performing its function-filtering blood-even if it has never done so. Similarly, the proto-self still has the function of indicating and regulating the homeodynamics of the organism. In the 
example of the objection, the homeodynamics of the subject is regulated by an external device and not by the proto-self. The proto-self is malfunctioning; however, the phenomenal character of the experience depends on the function of the proto-self, not on its actually performing such a function. According to the model, insofar as the interaction between the required brain structures - with the corresponding functionand the body is maintained, the organism can have conscious experiences. ${ }^{16}$

One might also worry about the relation between the proto-self and the proto-qualitative state. What happens if the modification of the proto-self happens spontaneously? What happens if a subject instantiates a proto-qualitative state that is not accompanied by the corresponding modification of the proto-self? The reply to these questions cannot be based on the idea that there cannot be a proto-qualitative state without a modification of the proto-self or the other way around. Surely, the modification of the proto-self corresponding to my visual experience as of a red patch is accompanied by the corresponding proto-qualitative state and, in normal circumstances, a proto-qualitative state is accompanied by a certain modification of the protoself. But both can happen independently of each other.

The answer to the former questions is that, in both circumstances, we do not have a conscious mental state. A conscious mental state is a complex constituted by the proto-self and the proto-qualitative state. Both are required to have a phenomenally conscious mental state, a mental state with the proper content; a state with the proper causal role. If one of their parts or the relation between them is missing, we have no complex. Both parts are required to fulfill a certain causal role, the role that allows the traits to have the function of indicating a certain centered feature.

Finally, I would like to stress that the proto-self and the proto-qualitative states are theoretical postulations. Damasio's version of the proto-self is a very plausible candidate for playing the proto-self role required by the theory. It is a matter of future empirical research to look for the structures with the causal role postulated by the theory. If such structures are not found in the brain, the proposed view would be false.

\section{Conclusion}

Defenders of situated and EC stress the relevance of the environment and the body in the explanation of cognition. Although some of them either deflate the role that representations play in such explanation or attempt to get rid of them, representationalism - the view that maintains that the phenomenal character of the experience is wholly determined by its representational content-is not incompatible with those views. In this article, I have argued that even if we assume a strong representationalist starting point, we should end up with the conclusion that our cognition constitutively depends upon body activity beyond that in the brain.

Representationalism is one of the most appealing theories in quest of naturalizing consciousness. However, there is strong empirical evidence in favor of the possibility of shifted spectrum without misrepresentation. Shoemaker has shown that the introduction of appearance properties reconciles the representationalist view with evidence, and Egan has shown that we should think of appearance properties as centered features or self-ascribed properties: the content of the experience is de se.

I have argued that the claim that the content of the experience is de se perfectly matches the phenomenological observation and helps explaining the subjective character of the experience. Furthermore, I have maintained that entertaining this kind of content constitutively depends on bodily activity (the activity that the protoself monitors and regulates). If this is right, the consequence that cognition is embodied immediately follows, at least insofar as cognition depends on consciousness.

\section{Acknowledgements}

The author is grateful to Marc Artiga, Axel Barceló, Denis Buehler, Ángeles Eraña, Manolo Martínez, David Pineda, and Pepa Toribio for discussion.

\section{Declaration of Conflicting Interests}

The author(s) declared no potential conflicts of interest with respect to the research, authorship, and/or publication of this article.

\section{Funding}

The author(s) disclosed receipt of the following financial support for the research, authorship, and/or publication of this article: This work was supported by the PAPIIT (IN400218).

\section{Notes}

1. For a summary on non-conscious perception, see Merikle and Daneman (1999). For discussion, see Block (2016), Peters et al. (2016), and Phillips (2016).

2. If hallucinations that are phenomenally indistinguishable from veridical perceptions are possible, certain radical theories of situated cognition are seriously jeopardized. Consider, for instance, Noë (2005), who maintains that perception does not depend on internal representation, but is rather constituted by the interaction between the mind and the world. In the case of a hallucination of a red apple, however, there is no red apple the mind is interacting with.

3. There are very diverse characterizations of such representational properties. Tye (1997, 2002), for instance, maintains that they are abstract, non-conceptual representations available for belief forming and rational control; Higher-Order Representational (HOR) theories 
(Carruthers, 2000; Lycan, 1996; Rosenthal, 2005) maintain that they have to be the target of a further representation to become conscious. Prinz (2012) holds that they are attended intermediate representations; Kriegel (2009) claims that they are representations that represent themselves.

4. The term "constitution" is used broadly to refer to relations such as realization, identity, and constituency. The aim is solely to distinguish these relations from a merely causal one. For further detail and taxonomy of relational claims, one might hold in relation to situated and embodied cognition see Prinz (2009).

5. For a detailed presentation of these and other empirical evidence for shifted spectrum and an argument against representationalism, see Block (2003, 2007b). For an attempt to deflate the relevance of these cases, see Allen (2017).

6. Egan considers the case of inverted spectrum. Many philosophers reject the metaphysical possibility of such scenarios. His analysis, however, can be applied mutatis mutandis to the case of shifted spectrum, as we are about to see.

7. This principle roughly corresponds to what Egan calls Sameness. Egan (2006) considers two inverted subjects, Ernie and Vert, and presents his Sameness desiderata as follows

Sameness: the appearance property that Ernie's visual experience attributes to Kermit is the same as the appearance property that Vert's visual experience attributes to, for example, cooked lobsters and ripe tomatoes (p. 501).

My Possible-Sameness is weaker than Egan's. PossibleSameness simply demands that the characterization of appearance properties makes room for the possibility of two shifted individuals correctly attributing the same appearance property to relevantly different objects. It should be noted, as Egan does, that Possible-Sameness and Difference do not impose contradictory demands on appearance properties. Difference requires that the appearance property that an individual attributes to the apple be different from the one $S_{b}$ attributes to it. PosSameness requires that the appearance property that the visual experience of $S_{a}$ attributes to an object $O_{1}$ can be the same as the one that the experience of $S_{b}$ attributes to an object of a different color.

8. Shoemaker also suggests a non-dispositional version of the form properties of the form currently producing $a$ phenomenally red experience in some observer. He rejects such a proposal because, in this case, appearance properties would not be properties that objects would have when not being observed.

9. Egan leaves one additional problem unresolved. We do not want to maintain that every object that is disposed to cause the same experience in me that the apple is disposed to cause shares with it its appearance properties. Certain kind of drugs might be disposed to cause experiences as of a red apple in me, but I do not thereby attribute any appearance property to the drugs. The object has to cause the experience in normal circumstances. This is a normative notion that, if we are interested in naturalistic theories, has to be unpacked by appealing to the same theory that explains the relation of representation. Consider the example of teleological theories of mental content (Millikan, 1984, 1989; Neander, 1991; Papineau, 1993). Very roughly, these theories maintain that a mental state $\mathrm{M}$ represents $\mathrm{C}$ if and only if $\mathrm{M}$ indicates $\mathrm{C}$ in normal conditions, where the notion of indication can be spelled out as a causally grounded tracking of information, and the normal conditions are determined by the function of $\mathrm{M}$. In other words, $\mathrm{M}$ represents $C$ because $M$ has the function of indicating $C$ and not other properties with which it causally correlates. In our example, the phenomenally conscious state would have the function of indicating red apples and not drugs, despite of indicating both of them. As I said above, it is very plausible that the characterization of the function of a trait commits us to embodied and/or situated views.

10. This is just a toy example for illustrative purposes. For further details and discussion, see, for example, Dretske (1981), Millikan (1984, 1989), Mossio et al. (2009), Neander (1991), and Schroeder (2004).

11. I have preferred to respect the name given by Damasio to this structure, but one should not be confused by it. There is nothing "self-ish" in the proto-self, and it is just a neural structure with the above-mentioned function.

12. In his most recent work, Damasio (2010) includes the cingulate cortex as part of the proto-self, and I do not think that this area is required. Damasio postulates this area because bilateral anterior lesion of the cingulate causes a condition known as akinetic mutism, that is described by Damasio (2000) as "suspended animation, internally as well as externally” (p. 176). However, akinetic mutism is usually characterized as a variant of minimally conscious states as suggested by the following observation by Laureys and Tononi (2008):

The interpretation is complicated by the fact that, in the rare instance in which such patients recover, there is usually amnesia for the akinetic episode, as in the original case of Cairns, though one patient who eventually recovered reported that she remembered the questions posed by the doctor but did not see a reason to respond. (p. 385)

13. $P Q_{1}$ doesn't have the function of indicating Transcranial magnetic stimulation (TMS) or any drug, even if both are disposed to cause its activation. For that reason, something like "via the particular visual path $P Q 1$ is included." In the case of vision, the normal conditions would also include particular lightning conditions. These normal conditions have to be fixed by the function $P Q_{1}$ if a teleological theory of mental content is true, as we saw in Note 9.

14. Note that the content of proto-qualitative states is not de se. There is nothing problematic here, because protoqualitative states do not have to satisfy all the desiderata presented in section "Representationalism and shifted spectrum."

15. I am grateful to Ned Block for raising this objection. 
16. It is worth stressing that the model of de se presentation presented here, upon which consciousness as I have argued depends, relies on the existence of a selfmaintained system.

17. The kind of possibility involved here is simply a metaphysical possibility, not even nomological possibility is required, although I see no reason to deny the latter.

\section{References}

Allen, K. (2017). A naive realist theory of colour. New York, NY: Oxford University Press.

Bermudez, L. (1998). The paradox of self-consciousness. Cambridge, MA: MIT Press.

Block, N. (2003). Mental paint. In M. Hahn, \& B. Ramberg (Eds.), Reflections and replies: Essays on the philosophy of Tyler Burge (pp. 165-200). Cambridge, MA: MIT Press.

Block, N. (2007a). Consciousness, accessibility, and the mesh between psychology and neuroscience. Behavioral and Brain Sciences, 30, 481-548.

Block, N. (2007b). Wittgenstein and qualia. Philosophical Perspectives, 21(1), 73-115.

Block, N. (2016). The Anna Karenina principle and skepticism about unconscious perception. Philosophy and Phenomenological Research, 2, 452-459.

Burge, T. (2007). Foundations of mind: Philosophical essays. New York, NY: Oxford University Press.

Byrne, A. (2004). What phenomenal consciousness is like. In R. Gennaro (Ed.), Higher-order theories of consciousness: An anthology (pp. 203-226). Amsterdam: John Benjamins Publishing Company.

Carruthers, P. (2000). Phenomenal consciousness: A naturalistic theory (1st ed.). Cambridge, UK: Cambridge University Press.

Castañeda, H.-N. (1966). "he": A study in the logic of selfconsciousness. Ratio, 8, 130-157.

Clark, A. (2008). Supersizing the mind: Embodiment, action, and cognitive extension. New York, NY: Oxford University Press.

Cummins, R. E. (1975). Functional analysis. Journal of Philosophy, 72, 741-764.

Damasio, A. (2000). The feeling of what happens: Body and emotion in the making of consciousness (1st ed.). Boston: Mariner Books.

Damasio, A. (2010). Self comes to mind: Constructing the conscious brain (1st ed.). New York: Pantheon.

Damasio, R. (1995). Descartes' error: Emotion, reason, and the human brain (1st ed.). New York, NY: Harper Perennial.

Di Paolo, E., \& Thompson, E. (2014). The enactive approach. In L. Shapiro (Ed.), The Routledge handbook of embodied cognition (pp. 68-78). London: Routledge.

Dretske, F. (1981). Knowledge and the flow of information. Cambridge, MA: MIT Press.

Dretske, F. (1988). Explaining behavior: Reasons in a world of causes. Cambridge, MA: MIT Press.

Duncan, S., \& Barrett, L. (2007). Affect is a form of cognition: A neurobiological analysis. Cognition and Emotion, 21, 1184-1211.

Egan, A. (2006). Appearance properties? Noûs, 40, 495-521.

Flanagan, J. (1993). Consciousness reconsidered. Cambridge, MA: MIT Press.
Gallagher, S., \& Zahavi, D. (2006). Phenomenological approaches to self-consciousness. Retrieved from http:// plato.stanford.edu/entries/self-consciousnessphenomenological/

Godfrey-Smith, P. (1994). A modern history theory of functions. Noûs, 28, 344-362.

Hutto, D., \& Myin, E. (2013). Radicalizing enactivism: Basic minds without content. Cambridge, MA: MIT Press.

Kraft, J. M., \& Werner, J. S. (1994). Spectral efficiency across the life span: Flicker photometry and brightness matching. Journal of American Optical Society, 11, 1113-1120.

Kriegel, U. (2009). Subjective consciousness: A selfrepresentational theory. New York, NY: Oxford University Press.

Laureys, S., \& Tononi, G. (2008). The neurology of consciousness: Cognitive neuroscience and neuropathology (1st ed.). Amsterdam: Academic Press.

Lewis, D. (1979). Attitudes de dicto and de se. Philosophical Review, 88, 513-543.

Lutze, M., Cox, N. J., Smith, V. C., \& Pokorny, J. (1990). Genetic studies of variation in Rayleigh and photometric matches in normal trichromats. Vision Research, 30, 149-162.

Lycan, G. (1996). Consciousness and experience. Cambridge, MA: MIT Press.

McLaughlin, P. (2001). What functions explain: Functional explanation and self-reproducing systems. Cambridge, UK: Cambridge University Press.

Merikle, P. M., \& Daneman, M. (1999). Conscious vs. unconscious perception. In M. S. Gazzaniga (Ed.), The new cognitive neuroscience (pp. 1295-1304). Cambridge, MA: MIT Press.

Millikan, G. (1984). Language, Thought and Other Biological Categories. Cambridge, MA: MIT Press.

Millikan, R. G. (1989). Biosemantics. Journal of Philosophy, 86, 281-297.

Mossio, M., Saborido, C., \& Moreno, A. (2009). An organizational account of biological functions. British Journal for the Philosophy of Science, 60, 813-841.

Neander, K. (1991). Functions as selected effects: The conceptual analyst's defense. Philosophy of Science, 58, 168-184.

Neitz, J., Neitz, M., \& Jacobs, G. (1993). More than three different cone pigments among people with normal color vision. Vision Research, 33, 117-122.

Neitz, M., \& Neitz, J. (1998). Molecular genetics and the biological basis of color vision. In R. K. W. G. Backhaus, \& J. Werner (Eds.), Color vision: Perspectives from different disciplines (pp. 101-104). Berlin, Germany: De Greuter.

Nida-Ruemelin, M. (2017). Self-awareness. Review of Philosophy and Psychology, 8, 55-82.

Noë, A. (2005). Action in perception. Cambridge: Bradford Books.

O'Regan, K. (2011). Why red doesn't sound like a bell: Understanding the feel of consciousness. Oxford, UK: Oxford University Press.

Papineau, D. (1993). Philosophical naturalism. Oxford: Blackwell.

Perry, J. (1979). The problem of the essential indexical. Noûs, 13, 3-21.

Peters, M., Kentridge, R., Phillips, I., \& Block, N. (2016). Does unconscious perception really exist? Continuing the ASSC20 debate. Retrieved from http://www.nyu.edu/gsas/ dept/philo/faculty/block/papers/2017.unc.symp.pdf 
Phillips, I. (2016). Consciousness and criterion: On blocks case for unconscious seeing. Philosophy and Phenomenological Research, 93, 419-451.

Pollen, D. A. (2008). Fundamental requirements for primary visual perception. Cerebral Cortex, 18, 1991-1998.

Prinz, J. (2009). Is consciousness embodied. In J. Prinz (Ed.), The Cambridge handbook of situated cognition (pp. 419436). Cambridge, UK: Cambridge University Press.

Prinz, J. (2012). The conscious brain. New York, NY: Oxford University Press.

Rosenthal, D. (2005). Consciousness and mind. New York, NY: Oxford University Press.

Rupert, R. (2009). Cognitive systems and the extended mind. Oxford, UK: Oxford University Press.

Schroeder, T. (2004). New norms for teleosemantics. In H. Clapin (Ed.), Representation in mind (pp. 91-106). Amsterdam: Elsevier.

Sebastián, M. Á. (2012). Experiential awareness: Do you prefer "it" to "me"? Philosophical Topics, 40, 155-177.
Shapiro, L. (2011). Embodied Cognition. New York, NY: Routledge.

Shoemaker, S. (1994). Phenomenal character. Noûs, 28(1), 21-38.

Shoemaker, S. (2000). Phenomenal character revisited. Philosophy and Phenomenological Research, 60, 465-467.

Stalnaker, C. (1999). Context and content: Essays on intentionality in speech and thought. New York, NY: Oxford University Press.

Tye, M. (1997). Ten problems of consciousness: A representational theory of the phenomenal mind. Cambridge, MA: MIT Press.

Tye, M. (2002). Consciousness, color, and content. Cambridge, MA: MIT Press.

Varela, F. J., Thompson, E., \& Rosch, E. (1991). The embodied mind: Cognitive science and human experience. Cambridge, MA: MIT Press.

Wilson, D. (2002). Strangers to ourselves: Discovering the adaptive unconscious. Cambridge, MA: Harvard University Press.

\section{About the Author}

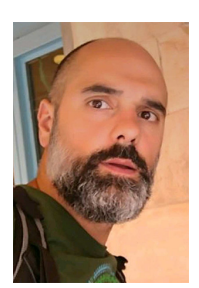

Miguel Ángel Sebastián is a Research Fellow at the Instituto de Investigaciones Filosoficas, at UNAM, Mexico. His research focuses on the philosophy of mind and cognitive sciences with deep interest in consciousness studies. 